\title{
Qualidade da colheita mecanizada de feijão (Phaseolus vulgaris) em dois sistemas de preparo do solo ${ }^{1}$
}

\author{
Quality of the mechanical harvesting of beans (Phaseolus vulgaris) under two tillage \\ systems
}

\author{
Rouverson Pereira da Silva ${ }^{2 *}$, Marcelo Tufaile Cassia ${ }^{3}$, Murilo Aparecido Voltarelli ${ }^{3}$, Ariel Muncio Compagnon ${ }^{3}$ \\ e Carlos Eduardo Angeli Furlani ${ }^{3}$
}

\begin{abstract}
RESUMO - Dentre as etapas de produção do feijoeiro a colheita é uma das mais importantes, porque pode interferir de maneira decisiva na qualidade e no custo de produção. Assim, objetivou-se avaliar a qualidade da operação da colheita mecanizada de feijão (Phaseolus vulgaris), cultivado sob preparo convencional e plantio direto. As variáveis analisadas foram: o nível de ruído emitido, calculado através de um medidor de pressão sonora; o desempenho operacional, sendo monitorado o consumo de combustível, a patinagem dos rodados e a velocidade de deslocamento do conjunto coletados em uma central digital (datalogger); e a operação de colheita quanto à matéria seca e densidade de palhada, e as perdas na colheita. A velocidade e os consumos horário e operacional apresentaram distribuição normal dos dados, enquanto que o nível de ruído apresentou distribuição assimétrica. As perdas na colheita mecanizada de feijão e a densidade de palhada apresentaram baixa variabilidade e distribuição normal. Assim, apenas o consumo horário e a produção de matéria seca de palhada apresentaram comportamento instável em relação ao controle estatístico de processo, enquanto os demais indicadores mostraram condições de manter a qualidade da operação de colheita tanto no preparo convencional de solo quanto no plantio direto.
\end{abstract}

Palavras-chave: Controle estatístico de processo (CEP). Desempenho operacional. Perdas na colheita. Recolhedoratrilhadora.

\begin{abstract}
Among the production stages of the bean plant, harvesting is one of the most important, because it can decisively affect both quality and production costs. Thus, the objective was to assess quality in the mechanized harvesting of beans (Phaseolus vulgaris), grown under conventional tillage and no-tillage systems. The variables analysed were: the noise level emitted, calculated using a sound-pressure meter; the operational performance, by monitoring fuel consumption, wheel-slippage, and displacement velocity of the machine, all collected digitally (datalogger); and the harvesting operation with regard to the dry matter and density of stubble, and to crop losses. The speed and the hourly and operational fuel consumption showed normal data distribution, while the noise level showed a skewed distribution. Losses in the mechanical harvesting of the beans, and stubble density, showed low variability and normal distribution. Therefore, only the hourly consumption and production of stubble dry-matter, showed unstable behavior in relation to the statistical process control, while the other indicators showed it possible to maintain quality in the harvesting operation under both conventional tillage and no-tillage systems.
\end{abstract}

Key words: Statistical process control (SPC). Operational performance. Harvesting losses. Bean pick-up machine.

\footnotetext{
*Autor para correspondência

${ }^{1}$ Recebido para publicação em 20/09/2011; aprovado em 19/06/2012

Projeto de pesquisa desenvolvido na Fazenda de Ensino, Pesquisa e Produção da Faculdade de Ciências Agrárias e Veterinárias de Jaboticabal

2Departamento de Engenharia Rural, Faculdade de Ciências Agrárias, Universidade Estadual Paulista "Júlio de Mesquita Filho", Via de Acesso Prof. Paulo Donato Castellane, s/nº, Jaboticabal-SP, Brasil, 14.884-900, rouverson@ fcav.unesp.br

${ }^{3}$ Departamento de Engenharia Rural, Universidade Estadual Paulista "Júlio de Mesquita Filho", Jaboticabal-SP, Brasil, marcelocassia@ agronomo.eng.br, murilo_voltarelli@hotmail.com, arielcompagnon@gmail.com, furlani@fcav.unesp.br
} 


\section{INTRODUÇÃO}

O feijoeiro (Phaseolus vulgaris L.) além de ser uma leguminosa importante ao consumo humano, sendo rica em proteínas e aminoácidos, também é uma cultura que pode ser utilizada para diversificação de renda em propriedades rurais (SILVA et al., 2004). Contudo, dentre as etapas de produção desta cultura, a colheita é uma das mais importantes uma vez que se a mesma for mal processada pode acarretar em perdas, danos mecânicos e provocar o escurecimento dos grãos interferindo de maneira decisiva na qualidade do produto e no seu valor comercial (SOUZA et al., 2004).

A colheita mecanizada pode ser direta ou indireta, sendo na primeira empregadas colhedoras combinadas, que realizam simultaneamente todas as operações, enquanto que na colheita indireta se utilizam equipamentos como o ceifador enleirador e a recolhedora-trilhadora em operações distintas (SILVA et al., 2008).

No Brasil, em virtude dos problemas inerentes à cultura e inexistência de uma ampla linha de produtos específicos e adequados para a cultura do feijão, bem como em muitos casos da inviabilidade do uso de colhedoras convencionais, Silva (1988) e Silva e Silveira (2004) relatam que a colheita dessa leguminosa tem sido realizada predominantemente de maneira indireta, com mecanização nas operações de recolhimento e trilha, sendo esta operação realizada por uma máquina denominada recolhedora-trilhadora.

Dentre os fatores que podem vir a interferir no desempenho operacional ou na qualidade da operação realizada pelo conjunto trator-recolhedora-trilhadora, as condições de desenvolvimento da cultura bem como os tratos culturais e as condições do terreno podem acarretar em perdas durante o processo de colheita (SILVA et al., 2008).

Furlani et al. (2008) relatam que o tipo de preparo de solo no terreno pode influenciar no desempenho operacional do trator, sendo que as áreas de plantio direto apresentaram menores índices de patinagem, contudo com maior consumo de combustível em algumas operações.

Autores, a exemplo de Gabriel Filho et al. (2010), estudaram o desempenho operacional de tratores agrícolas em diferentes condições de tipos e preparo de solo, bem como Silva et al. (2008) que avaliaram o desempenho do conjunto trator-recolhedora-trilhadora na operação de colheita de feijão, contudo em nenhum caso utilizando ferramentas que buscam manter a qualidade nas operações. De acordo com Toledo et al.
(2008) o controle estatístico de processo (CEP) busca melhoria da qualidade do processo pela redução da variabilidade, porém não existe processo ausente de variabilidade, assim a solução é manter o processo dentro de padrões de estabilidade.

Diante o exposto, pressupõe-se que os sistemas de preparo do solo podem afetar o desempenho operacional do conjunto trator-recolhedora-trilhadora e que o emprego de ferramentas de qualidade auxilie na análise das variáveis buscando a qualidade no processo; este trabalho teve como objetivo avaliar a operação da colheita mecanizada de feijão cultivado sob os sistemas de preparo convencional do solo e plantio direto, sob a estatística descritiva e o controle estatístico de processo (CEP).

\section{MATERIAL E MÉTODOS}

O experimento foi conduzido na Área Demonstrativa e Experimental de Irrigação, localizada na Fazenda de Ensino, Pesquisa e Produção - FEPP da UNESP/Jaboticabal, nas coordenadas geodésicas $21^{\circ} 14^{\prime}$ de latitude Sul e $48^{\circ} 17^{\prime}$ de longitude Oeste, com altitude média de 615 metros, declividade em torno de $8 \%$ e clima Aw de acordo com a classificação de Köeppen.

O solo da área amostral foi classificado como Latossolo Vermelho eutroférrico, conforme o Sistema Brasileiro de Classificação de Solos (EMPRESA BRASILEIRA DE PESQUISA AGROPECUÁRIA, 2006).

A área foi manejada sob um sistema de irrigação do tipo pivô central, que abrange uma área de 3,3 ha, que vinha sendo manejada com sucessão de culturas utilizando-se o feijoeiro na época mais seca do ano e milho na época mais úmida, sob os sistemas de Preparo Convencional (PC) e Plantio Direto (PD).

$\mathrm{Na}$ entressafra do ano de 2004, para a instalação do presente ensaio com a cultura do feijoeiro, aplicouse o herbicida glifosato na dose de $4,0 \mathrm{~L} \mathrm{ha}^{-1}$ em toda a área, e em seguida foi realizada a primeira aração e segunda aração nas parcelas sob sistema de PC e, em seguida, três gradagens para a completa incorporação dos resíduos vegetais. A semeadura foi realizada no mês de julho de 2004 sendo em um dia no sistema de PD e no dia seguinte no PC, utilizando a cultivar IACCarioca precoce.

A cultura foi implantada no espaçamento entre linhas de $0,45 \mathrm{~m}$ e 14 sementes $\mathrm{m}^{-1}$, considerando-se a porcentagem de germinação em torno de $92 \%$, originando 
a população de aproximadamente 285.000 plantas ha-1 . A adubação de semeadura utilizada foi $50 \mathrm{~kg} \mathrm{ha}^{-1}$ de uréia, $400 \mathrm{~kg} \mathrm{ha}^{-1}$ de superfosfato simples, e $75 \mathrm{~kg} \mathrm{ha}^{-1}$ de cloreto de potássio, de acordo com análise química do solo. $\mathrm{Na}$ adubação de cobertura foi aplicado $150 \mathrm{~kg} \mathrm{ha}^{-1}$ de uréia, aos 27 dias após a emergência.

A colheita foi realizada por uma recolhedoratrilhadora DOUBLE MASTER III, com sistema de fluxo axial, tracionada e acionada pela TDP do trator, que opera com largura de trabalho de 1,62 m e rotação do cilindro trilhador de $540 \mathrm{rpm}$. A recolhedora foi tracionada por um trator instrumentado da marca Valtra, modelo BM100 4x2 com tração dianteira auxiliar (TDA), potência no motor de $73,6 \mathrm{~kW}(100 \mathrm{cv})$ a $2.300 \mathrm{rpm}$, equipado com pneus 14.9-24 no eixo dianteiro e 23.126 no eixo traseiro. Durante a operação de semeadura, o trator operou na marcha $\mathrm{L} 4$, com rotação de $1.900 \mathrm{rpm}$, visando a velocidade de $5,0 \mathrm{~km} \mathrm{~h}^{-1}$.

O delineamento experimental adotado foi inteiramente casualizado, com dois sistemas de preparo do solo (PC e PD) e nove repetições, sendo as parcelas demarcadas com $30 \mathrm{~m}$ de comprimento, com intervalos de $15 \mathrm{~m}$ entre si. As variáveis analisadas foram: o nível de ruído emitido, o desempenho operacional do conjunto e a qualidade da operação de colheita.

O nível de ruído $(\mathrm{R})$ foi calculado através de um medidorde pressãosonora damarcaExtech Instruments ${ }^{\circledR}$, modelo 407706, com escalas de baixa e alta intensidade de 40 a 80 e 80 a $120 \mathrm{~dB}$, respectivamente. O medidor de nível de pressão sonora foi calibrado com um áudio calibrador, marca Extech Instruments ${ }^{\circledR}$, modelo 407744 (nível sonoro: $94 \mathrm{~dB}$ a $1000 \mathrm{~Hz}\left(23^{\circ}\right.$ ); distorção: menor que $5 \%$ ) as determinações se basearam no método NBR - 9999 (ASSOCIAÇÃO BRASILEIRA DE NORMAS TÉCNICAS, 1987). O trator utilizado possui instrumentação para avaliar as variáveis inerentes ao desempenho operacional, sendo no presente ensaio monitorado o consumo de combustível (C.H. e C.O.), a patinagem dos rodados dianteiro (PRD) e traseiro (PRT), e a velocidade de deslocamento do conjunto (V) coletados em uma central digital (datalogger).

Quanto à operação de colheita foram determinadas a matéria seca (MS) e densidade de palhada (DP), obtidas através de coletas em armação de $0,25 \mathrm{~m}^{2}$ ao acaso nas parcelas e levadas à estufa de circulação forçada a $105^{\circ} \mathrm{C}$ por 48 horas. As perdas na colheita, em que utilizou-se uma armação retangular de madeira com área de 2,0 $\mathrm{m}^{2}(1,62 \times 1,24 \mathrm{~m})$, onde foram determinadas as perdas na pré-colheita com amostras coletadas antes da entrada da colhedora, e as perdas após a colheita. Para as perdas na pré-colheita e no arranquio, as armações foram colocadas nas parcelas demarcadas, contudo os valores encontrados foram considerados desprezíveis.

Para a determinação das perdas totais na colheita (PT) a armação foi colocada ao acaso na parcela após a passagem da máquina, no sentido transversal ao movimento da recolhedora.

Os dados foram tabulados e analisados estatisticamente pela estatística descritiva e por meio do controle estatístico de processo, utilizando-se como ferramenta, as cartas de controle para variáveis, sendo utilizado o programa computacional Minitab $15^{\circledR}$, a fim de identificar causas de variabilidade não inerentes ao processo.

\section{RESULTADOS E DISCUSSÃO}

Os resultados de estatística descritiva para os parâmetros de medida de tendência central (média, mediana e amplitude) e de dispersão (desvio padrão e coeficiente de variação) para nível de ruído, desempenho operacional e qualidade de colheita estão apresentados na Tabela 1 .

Para o nível de ruído $(\mathrm{R})$ observa-se que a média e a mediana encontraram-se próximas, e apesar de os valores de desvio padrão e do coeficiente de variação (CV) serem muito baixos, a distribuição dos dados foi assimétrica com coeficiente de assimetria (Cs) positivo.

Para as variáveis relacionadas ao desempenho operacional do conjunto observa-se para o consumo de combustível que tanto para (C.H.) quanto para (C.O.) os dados apresentaram média e mediana próximos, com baixos índices de desvio padrão e (CV), sendo que ambas as variáveis apresentaram distribuição normal pelo teste de Anderson-Darling.

Para velocidade de deslocamento (V) observa-se baixa variabilidade, com valores da média e mediana próximos, que fica evidenciado pelos baixos valores de desvio padrão e (CV), apresentando distribuição normal, o que também foi obtido para (PRD) que por sua vez apresentaram (CV), amplitude e desvio padrão elevados, apesar de possuírem os coeficientes de assimetria (Cs) e de curtose (Ck) próximos de zero. Para a (PRT) observou-se também alta variabilidade nos dados com valores da média e mediana distantes entre si, elevados valores de amplitude e (CV), bem como (Ck) distante de zero e (Cs) positivo caracterizando uma distribuição assimétrica.

Os valores de (PT) tiveram baixa variabilidade, sendo uma característica bastante interessante ao se tratar 
Tabela 1 - Estatística descritiva para as variáveis relacionadas ao nível de ruído $(\mathrm{R})$, consumo horário $(\mathrm{CH})$ e operacional $(\mathrm{CO})$ de combustível, velocidade de deslocamento (V), patinagem do rodado dianteiro (PRD) e traseiro (PRT), perdas totais na colheita (PT), matéria seca de palhada colhida (MS) e densidade palhada (DP)

\begin{tabular}{llllllllll}
\hline \multicolumn{1}{c}{ Parâmetros } & $\mathrm{R}(\mathrm{dB})$ & $\begin{array}{c}\mathrm{C} . \mathrm{H} . \\
\left(\mathrm{L} \mathrm{h}^{-1}\right)\end{array}$ & $\begin{array}{c}\mathrm{C} . \mathrm{O} . \\
\left(\mathrm{L} \mathrm{ha}^{-1}\right)\end{array}$ & $\begin{array}{c}\mathrm{V} \\
\left(\mathrm{km} \mathrm{h}^{-1}\right)\end{array}$ & $\begin{array}{c}\text { PRD } \\
(\%)\end{array}$ & $\begin{array}{c}\text { PRT } \\
(\%)\end{array}$ & $\begin{array}{c}\text { PT } \\
\left(\mathrm{kg} \mathrm{ha}^{-1}\right)\end{array}$ & $\begin{array}{c}\mathrm{MS} \\
\left(\mathrm{kg} \mathrm{ha}^{-1}\right)\end{array}$ & $\begin{array}{c}\mathrm{DP} \\
\left(\mathrm{g} \mathrm{L}^{-1}\right)\end{array}$ \\
\hline Média & 88,8 & 10,7 & 11,4 & 4,9 & 8,2 & 5,8 & 88,8 & 4,9 & 8,2 \\
Mediana & 88,0 & 10,5 & 11,1 & 4,7 & 7,9 & 3,6 & 88,0 & 4,7 & 7,9 \\
Amplitude & 8,0 & 2,5 & 4,4 & 2,0 & 18,8 & 20,9 & 8,00 & 2,00 & 18,8 \\
Desvio padrão & 1,85 & 0,69 & 1,41 & 0,77 & 5,12 & 5,52 & 1,85 & 0,77 & 5,12 \\
CV $(\%)$ & 2,09 & 6,46 & 12,37 & 15,78 & 62,21 & 96,08 & 2,09 & 15,78 & 62,21 \\
Cs $(\%)$ & 1,45 & 0,80 & 0,23 & 0,35 & 0,56 & 1,87 & 1,45 & 0,35 & 0,56 \\
Ck $(\%)$ & 2,75 & $-0,07$ & $-1,17$ & $-1,57$ & 0,08 & 3,27 & 2,75 & $-1,57$ & 0,08 \\
AD & $1,390^{\mathrm{A}}$ & $0,481^{\mathrm{N}}$ & $0,358^{\mathrm{N}}$ & $1,101^{\mathrm{N}}$ & $0,280^{\mathrm{N}}$ & $1,545^{\mathrm{A}}$ & $0,734^{\mathrm{N}}$ & $0,605^{\mathrm{N}}$ & $0,484^{\mathrm{N}}$ \\
\hline
\end{tabular}

CV: coeficiente de variação, Cs: coeficiente de assimetria, Ck: coeficiente de curtose; AD: teste de normalidade de Anderson-Darling ( ${ }^{\mathrm{N}}$ : distribuição normal; ${ }^{\text {A: }}$ distribuição assimétrica)

de amostragem de perdas, onde normalmente ocorre elevada variabilidade espacial.

Contudo por se tratar de uma área de experimento instalado e manejado adequadamente, observou valores de média e mediana bastante próximos entre si e os valores de desvio padrão e (CV) também foram baixos, caracterizando a distribuição normal. A (MS) e (DP) tiveram uma distribuição normal para os pontos avaliados, sendo que para a produção de matéria seca se observou uma variabilidade relativamente baixa dos pontos, com coeficiente de variação considerado bom, e para a densidade da palhada observou-se uma elevada variabilidade, possivelmente devido à variabilidade espacial do comportamento no desenvolvimento da cultura.

Na Figura 1 são apresentadas as cartas de controle para os valores dos níveis de ruído do conjunto e para as variáveis do desempenho operacional do conjunto trator-recolhedora-trilhadora avaliados, para os dois sistemas de preparo de solo. Para os níveis de ruído (R) do conjunto avaliado observa-se que tanto para as amostras em preparo convencional (PC) quanto para plantio direto (PD) os índices mantiveram sob controle estatístico, ou seja, em nenhum ponto os índices ultrapassaram os limites de controle (LSC e LIC), contudo em ambos os casos tiveram médias em torno dos $90 \mathrm{~dB}$ o que deveria levar a restringir a exposição do operador ao mesmo em 5 horas diárias.

Os valores encontrados condizem com resultados de Silva et al. (2004) onde os níveis de ruído em colhedoras combinadas na colheita de milho ultrapassaram os limites estabelecidos pela norma, bem como Souza et al. (2004), ao avaliar uma recolhedora-trilhadora de feijão, relataram que os níveis de ruído estavam acima do limite estabelecido pela norma NBR - 15.

Observa-se ainda nas cartas de controle, que para as áreas de preparo convencional (PC) houve uma maior amplitude entre os pontos amostrais possivelmente devido a pequenas irregularidades na superfície do terreno, que podem ser refletidas na determinação dos limites de controle, ficando mais amplos que na área de plantio direto (PD), onde se obtém inclusive maior controle sobre a variável analisada.

Nas cartas de controle para o consumo horário ou volumétrico (C.V.) observa-se que, assim como para a patinagem dos rodados, nas áreas de preparo convencional há menor variabilidade do consumo de combustível, possivelmente interligado ao comportamento da variável anterior.

Contudo, apesar da redução na variabilidade dos dados encontrados, ocorreu um ponto fora dos limites de controle para área de preparo convencional, 
Figura 1 - Carta de controle para nível de ruído (R), consumo horário $(\mathrm{CH})$ e operacional $(\mathrm{CO})$ de combustível, em áreas de preparo convencional $(\mathrm{PC})$ e plantio direto $(\mathrm{PD})$
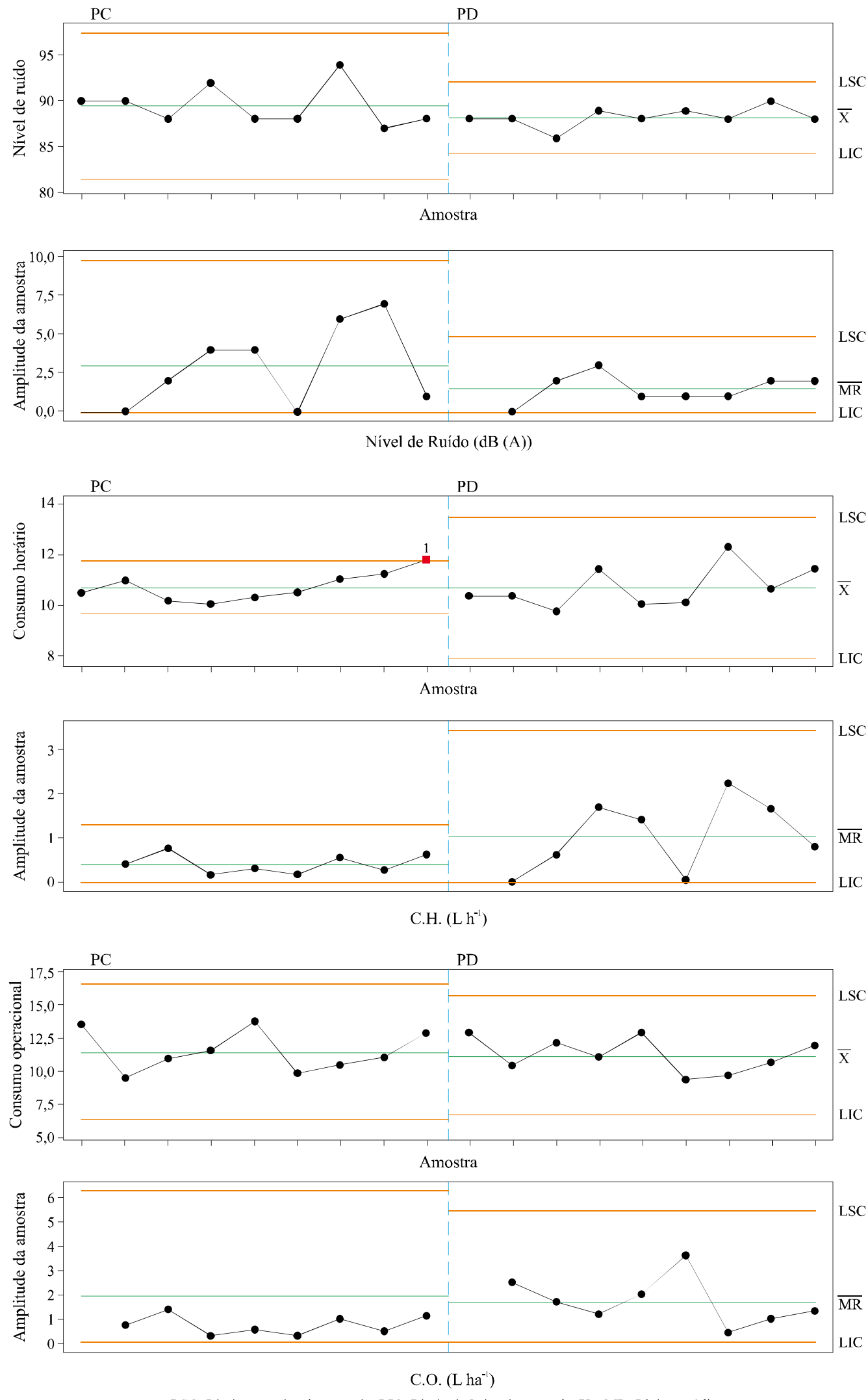

LSC: Limite superior de controle; LIC: Limite inferior de controle, X e MR: Linhas médias. 
caracterizando instabilidade do comportamento do consumo de combustível nesta operação. Fernandes, Silveira e Rinaldi (2008) trabalhando em avaliação do custo energético em diferentes operações agrícolas mecanizadas, encontraram o menor consumo horário de combustível no sistema de plantio direto.

Resultados opostos foram encontrados por Furlani et al. (2008) que relataram que a semeadoraadubadora em relação ao consumo horário de combustível não sofreu influencia no preparo de solo por meio do método convencional. Nas cartas de controle para o consumo operacional (C.O.) se observa que em ambos os sistemas de preparo de solo, a variável se comportou de maneira semelhante, se mostrando estável para os dois sistemas avaliados.

Na Figura 2 estão apresentadas as cartas de controle para velocidade do conjunto $\left(\mathrm{km} \mathrm{h}^{-1}\right)$, para os dois sistemas de preparo de solo avaliados, foi observado para ambos os sistemas de preparo que os valores se mantiveram estáveis, tanto para as cartas de valores individuais quanto para as cartas de amplitude móvel, se mostrando sob controle estatístico.

Vale observar ainda que as médias da velocidade para ambos os tratamentos se mantiveram próximos a $5 \mathrm{~km} \mathrm{~h}^{-1}$, Garcia et al. (2005) avaliando o desempenho operacional do conjunto trator-recolhedora de feijão relatam que as menores perdas podem ser encontradas nas maiores velocidades e umidade dos grãos, enquanto Tertuliano et al. (2009) trabalhando com colhedora autopropelida, relatam que os maiores danos visíveis eram encontrados na velocidade de $8,8 \mathrm{~km} \mathrm{~h}^{-1}$, enquanto Silva et al. (2008) trabalhando com o conjunto tratorrecolhedora-trilhadora encontraram os menores valores de perdas na velocidade de $4,9 \mathrm{~km} \mathrm{~h}^{-1}$.

Nas cartas de controle para patinagem dos rodados dianteiros (PRD) e traseiros (PRT), observase que em ambos os eixos (dianteiro e traseiro), a patinagem dos rodados se mantiveram estáveis sob o controle estatístico, não ultrapassando os limites de controle em nenhum ponto amostral.

Observa-se ainda que, ao contrário dos níveis de ruído, os índices de patinagem em ambos os eixos obtiveram uma menor variabilidade nas amostras nas áreas de preparo convencional, que determinou uma menor amplitude entre os limites de controle, aumentando a confiabilidade do processo.

O aumento da variabilidade na patinagem dos rodados nas áreas de plantio direto pode estar relacionado com a presença de palha na superfície de maneira desuniforme, que afeta o contato do pneu com o solo em diversos momentos.

Gabriel Filho et al. (2010) e Gabriel Filho et al. (2004) trabalhando com diferentes velocidades, tipo de solo e coberturas vegetais confirmam o fato de que em solo firme e sem cobertura vegetal o desempenho do trator é maior e que em solo com cobertura vegetal há uma tendência de aumentar os índices de patinagem trazendo com isso uma perda de tração pelo trator, respectivamente.

Na Figura 3 estão apresentadas as cartas de controle para as variáveis relacionadas à qualidade da operação de colheita, nas cartas de controle para produção de matéria seca pela cultura (MS) observa-se que para os dois sistemas de preparo de solo a variável se comportou de maneira bastante semelhante ao longo dos pontos amostrais, contudo para a área de preparo convencional detectou-se um ponto amostral acima do LSC sendo característico de um local na área onde a cultura produziu uma quantidade superior de matéria seca, tornando a variável fora de controle estatístico.

Em relação à densidade da palhada produzida (DP), observou-se para o preparo convencional maior variabilidade dos dados amostrados, sempre com valores acima ou abaixo dos observados nas áreas de plantio direto; contudo pelas cartas de controle a variável se mostrou estável, dentro dos limites de controle estabelecidos pelo programa.

Nas cartas de controle para as perdas totais na colheita mecanizada do feijão (PT) pode-se observar que para ambos os sistemas de preparo de solo a variável manteve-se sob controle estatístico, sendo a variabilidade dos valores obtidos semelhantes entre os tratamentos.

Toledo et al. (2008) na colheita mecanizada de soja encontraram para a mesma variável valor fora de controle estatístico, bem como Mesquita et al. (2002) e Campos et al. (2005) relataram que, em se tratando de perdas na colheita costuma-se haver um coeficiente de variação elevado, devido a variabilidade da amostra. Johann et al. (2010) relataram que a variabilidade espacial das perdas totais causadas na colheita semimecanizada na cultura do feijoeiro se mostrou abaixo da média encontrada na literatura.

Em estudo sobre espacialização de perdas na colheita de feijão ocasionados por uma recolhedoratrilhadora Souza et al. (2010) verificaram que há uma elevada variação na área, sendo necessária a regulagem especifica da máquina. 
Figura 2 - Carta de controle para velocidade de deslocamento (V), patinagem dos rodados dianteiro (PRD) e traseiro (PRT), áreas de preparo convencional (PC) e plantio direto (PD)
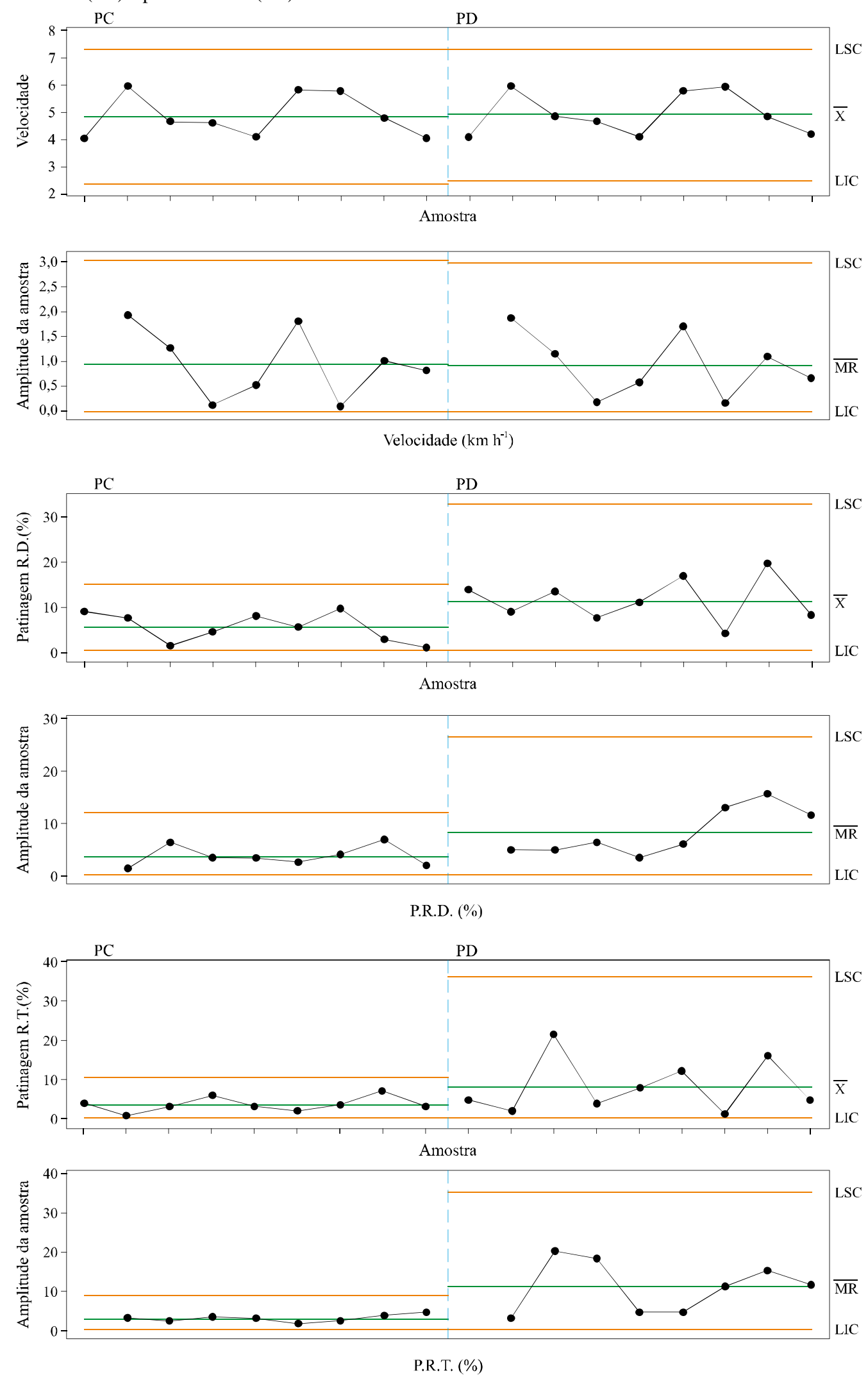

LSC: Limite superior de controle; LIC: Limite inferior de controle, X e MR: Linhas médias. 
Figura 3 - Carta de controle para matéria seca de palhada colhida (MS) e densidade da palhada (DP) e perdas totais na colheita (PT), em áreas de preparo convencional (PC) e plantio direto (PD)
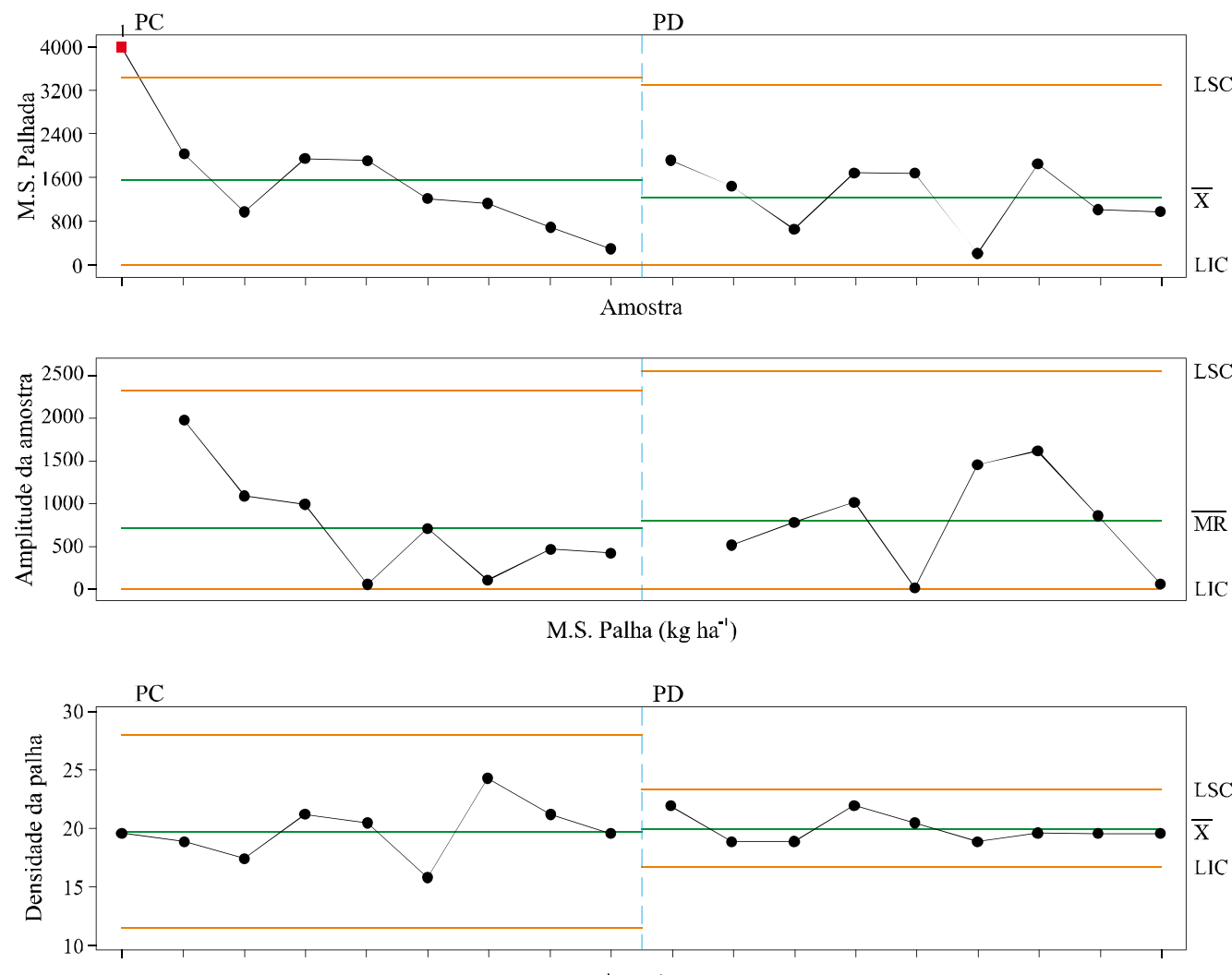

Amostra
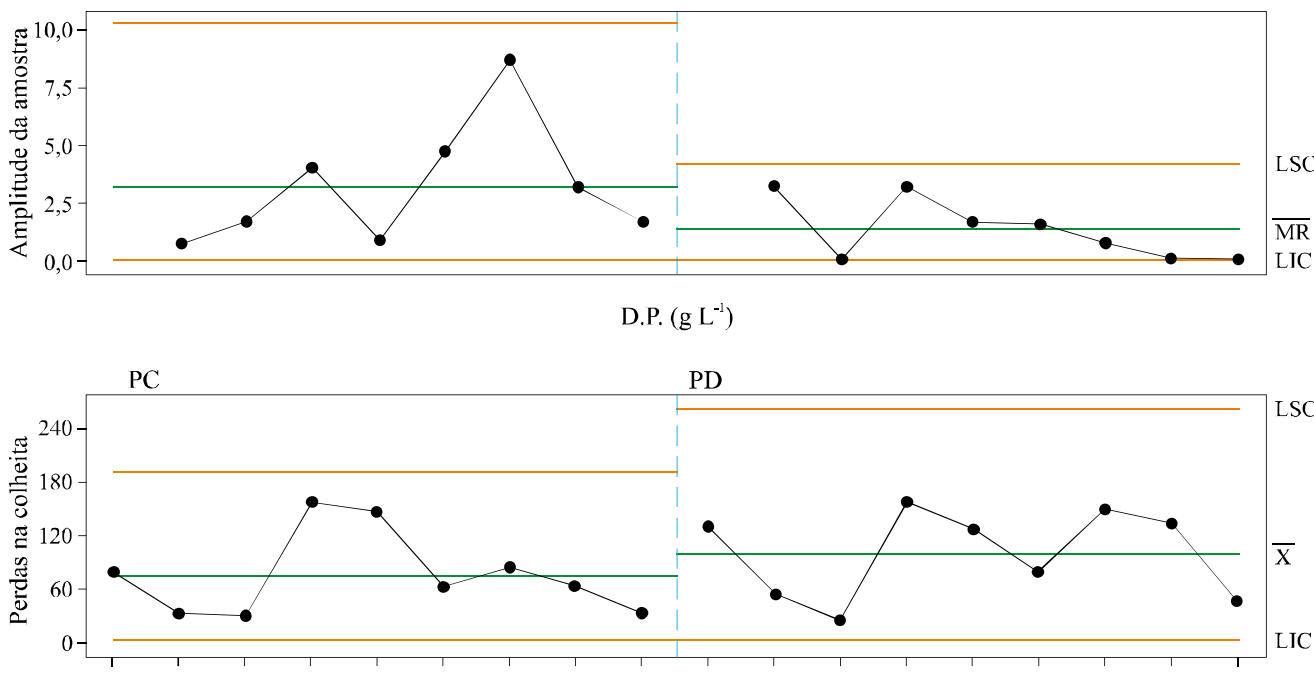

Amostra

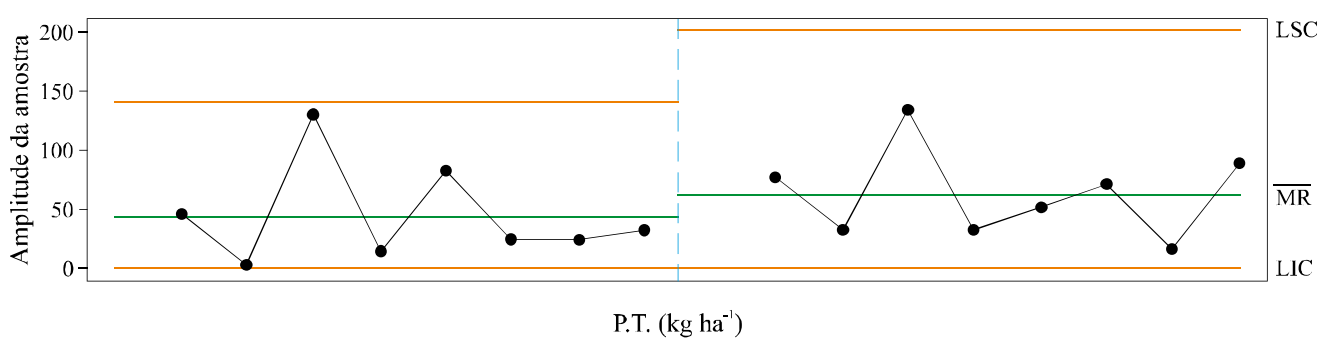

LSC: Limite superior de controle; LIC: Limite inferior de controle, X e MR: Linhas médias. 


\section{CONCLUSÕES}

1. A velocidade e os consumos horário e operacional apresentaram distribuição de probabilidade normal, enquanto que o nível de ruído apresentou distribuição assimétrica;

2. As perdas na colheita mecanizada de feijão, bem como a produção de matéria seca da cultura, e a densidade da palhada apresentaram baixa variabilidade e distribuição de probabilidade normal;

3. A patinagem do rodado dianteiro obteve distribuição normal quando comparada ao rodado traseiro que apresentou distribuição assimétrica com coeficiente de simetria positivo;

4. Apenas o consumo horário e a produção de matéria seca apresentaram comportamento instável em relação ao controle estatístico de processo enquanto os demais indicadores mostraram condições de manter a qualidade da operação de colheita tanto no preparo convencional de solo quanto no plantio direto.

\section{REFERÊNCIAS}

ASSOCIAÇÃO BRASILEIRA DE NORMAS TÉCNICAS. NBR 9999: Medição do nível de ruído, no posto de operação de tratores e máquinas agrícolas. Rio de Janeiro, 1987. 21 p.

AMBROSANO, E. J. et al. Feijão. In: RAI J, B. Van; CANTARElA, H.; QUAGGiO, J. A.; FURLANI, A. M. C. (Ed.) Recomendações de adubação e calagem para o Estado de São Paulo. Campinas: IAC, p.194-195, 1996a (Boletim Técnico 100).

CAMPOS, M. A. O. et al. Análise de perdas na colheita mecanizada de soja no estado de Minas Gerais. Engenharia Agrícola, v. 25, n. 01, p. 207-213, 2005.

CORTEZ, J. W. et al. Efeito residual do preparo de solo e velocidade de deslocamento na operação de semeadura de Crotalária juncea. Scientia Agraria, v. 09, n. 03, p. 357362, 2008.

EMPRESABRASILEIRADEPESQUISAAGROPECUÁRIA. Centro Nacional de Pesquisa de Solos. Sistema brasileiro de classificação de solos. 2. ed. Brasília: Embrapa Produção de Informação; Rio de Janeiro: Embrapa Solos, 2006.

FERNANDES, H. C., SILVEIRA, J. C. M., RINALDI, P. C. N. Avaliação do custo energético de diferentes operações agrícolas mecanizadas. Ciência e Agrotecnologia, v. 32, n. 05, p. 15821587, 2008.
FURLANI, C. E. A. et al. Semeadora-adubadora: exigências em função do preparo do solo, da pressão de inflação do pneu e da velocidade. Revista Brasileira de Ciência do Solo, v. 32, p. 345-352, 2008.

GABRIEL FILHO, A. et al. Desempenho de um trator operando em solo com diferentes tipos de cobertura vegetal. Engenharia Agrícola, v. 24, n. 03, p. 781-789, 2004.

GABRIEL FILHO, A. et al. Desempenho de trator agrícola em três superfícies de solo e quatro velocidades de deslocamento. Revista Brasileira de Engenharia Agrícola e Ambiental, v. 14, n. 03, p. 333-339, 2010.

GARCIA, R. F. et al. Desempenho operacional de conjunto trator-recolhedora de feijão. Engenharia Agrícola, v. 25, n. 01, p. 199-206, 2005.

JOHANN, J. A. et al. Variabilidade espacial da rentabilidade, perdas na colheita e produtividade do feijoeiro. Engenharia Agrícola, v. 30, n. 04, p. 700-714, 2010.

MESQUITA, C. M. et al. Perfil da colheita mecânica da soja no Brasil: safra 1998/1999. Engenharia Agrícola, v. 22, n. 03, p. 398-406, 2002.

MINITAB. MINITAB 15 Statistical Software ${ }^{\circledR}$ Minitab Inc., 2007.

SILVA, J. G. Colheita mecânica. In: ZIMMERMANN, M. J. O.; ROCHA, M.; YAMADA, T.Cultura do feijoeiro, fatores que afetam a produtividade. Piracicaba: Associação Brasileira para Pesquisa de Potássio e do Fosfato, 1988.p. 345-356.

SILVA, J. G. Mecanização sem esforço. Cultivar máquinas, v. 03, n. 36, 2004. 10 p. (Encarte: Caderno Técnico).

SILVA, J. G.; SILVEIRA, P. M. Colheita mecanizada do feijoeiro. Informe Agropecuário, v. 25, n. 223, p. 138-144, 2004.

SILVA, R. P. et al. Avaliação do nível de ruído em colhedoras combinadas. Engenharia Agrícola, v. 24, n. 02, p. 381-387, 2004.

SILVA, R. P. et al. Desempenho operacional do conjunto trator-recolhedora-trilhadora de feijão. Ciência Rural, v. 38, n. 05, p. 1286-1291, 2008.

SOUZA, C. M. A. et al. Espacialização de perdas e da qualidade do feijão em colheita semimecanizada. Acta Scientiarum. Agronomy, v. 32, n. 02, p. 201-208, 2010.

SOUZA, L. H. et al. Níveis de ruído emitidos por uma recolhedora-trilhadora de feijão. Engenharia Agrícola, v. 24, n. 03, p. 745-749, 2004.

TERTULIANO, P. C. et al. Qualidade de sementes de feijão colhidas por colhedora autopropelida em sistema semimecanizado. Engenharia Agrícola, v. 29, n. 01, p. 81-90, 2009.

TOLEDO, A. et al. Caracterização das perdas e distribuição de cobertura vegetal em colheita mecanizada de soja. Engenharia Agrícola, v. 28, n. 04, p. 710-719, 2008. 